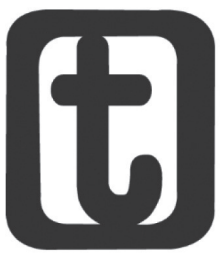

\title{
MORADOR DE RUA: CAUSAS, ENTRAVES E SERVIÇOS OFERTADOS
}

\author{
Street resident: causes, barriers and services offered
}

\author{
Elucleia Oliveira Balieiro* \\ Carla Patrícia Dias Soares* \\ Eliana de Araújo Vieira***
}

(cC) BY-NC

\section{RESUMO}

O morador de rua é entendido como a pessoa que reside na rua, e utiliza o espaço da rua ou albergues públicos para pernoite. O intuito do trabalho foi analisar quais as perspectivas por parte de moradores de rua, identificados em Montes Claros (MG), em sair da situação na qual se encontram em referência aos serviços públicos ofertados para este fim. Tratou-se de um estudo transversal, descritivo, de caráter qualitativo. O lócus de pesquisa constituiu nas unidades/serviço de atendimento aos moradores de rua em Montes Claros (MG): Centro de Referência Especializado para População em Situação de Rua (Centro Pop), o Serviço Especializado em Abordagem Social, e o Consultório na Rua. Quanto ao universo de pesquisa, foi composto tanto por moradores de rua, quanto por profissionais das unidades/serviço suprareferidos.

\section{PALAVRAS-CHAVE}

Morador de Rua. Causas. Serviços Públicos.

\footnotetext{
* Assistente Social. Assistente Social efetiva pela Prefeitura Municipal de Espinosa, Minas Gerais. Endereço Profissional: Rua Dom João VI, n 10, Bairro São Cristóvão, Espinosa/MG, 39510-000. E-mail: <elucleia.o.balieiro@hotmail.com>.

** Assistente Social. Técnica de Enfermagem na ESF Morrinhos. Endereço Profissional: Rua Melo Viana, 550 - Morrinhos, Montes Claros - MG, 39400-427. E-mail: <carlapattydias@hotmail.com>. *** Assistente Social. Mestre em Ciências da Educação. Coordenadora do Centro de Referência de Assistência Social (CRAS), do território Maracanã, em Montes Claros (MG). Endereço profissional: Av. Brasília, 538 - Maracanã, Montes Claros - MG, 39403-070. E-mail: <eliaravieira@hotmail.com>.
} 


\section{ABSTRACT}

The homeless is understood as the person who lives on the street and use the street space or public shelters at night. The aim of the work was to analyze the outlook by homeless people identified in Montes Claros (MG), getting out of the situation in which they are in reference to public services offered to this end. This was a cross study, descriptive, qualitative, and critical-dialectical approach. The research locus constituted in units/service care for the homeless in Montes Claros (MG): Specialized Reference Center for Population Homeless (Pop Centre), the Specialized Service for Social Approach, and the Clinic in Street. As for the universe of study was made up of both the homeless, as by professionals of units/above-mentioned service.

\section{KEYWORDS}

Homeless. Causes. Public services.

Submetido em: 20/11/2016

Aceito em: 20/9/2017

\section{INTRODUÇÃO}

Quantas vezes nos deparamos com moradores de rua em nosso cotidiano? Qual a nossa percepção quanto a essas pessoas e a situação em que se encontram? Ou nem sequer paramos para refletir, e somos indiferentes? Mattos e Ferreira (2004) relatam que alguns as veem como perigosas, outros como "vagabundas", muitos tem receio de serem abordados por pedido de esmola, há aqueles que sentem pena, em atitude mais violenta alguns chegam a xingá-las e até mesmo agredi-las de diversas formas; sendo brutalidades estas que marcam comumente nosso ambiente urbano. São as inquietações e indignações proporcionadas por essa análise, pelo fundamento de buscar entender o fenômeno em estudo e contribuir com a reflexão sobre o tema que conduziu esta pesquisa.

No que se refere ao conceito e maior entendimento do público pesquisado, cabe salientar alguns esclarecimentos. De acordo com a Política Nacional Para a População em Situação de Rua, entende-se como população em situação rua, o grupo populacional heterogêneo que possui em comum a pobreza extrema, a fragilidade dos vínculos familiares e a ausência de moradia convencional regular, utilizando áreas degradadas e logradouros públicos como espaço de moradia ou sustento (BRASIL, 2009a). Concordando com Escorel (2000), todas as pesquisas apontam que não existe apenas uma caracterização da população em situação 
de rua, mas sim populações, com diferentes características. Vieira, Bezerra e Rosa (2004) afirmam que seria possível determinar distintas situações quanto à permanência na rua: ficar na rua momentaneamente, estar na rua - a pouco tempo, ser da rua continuamente; o que possibilita a caracterização da população de rua em vários segmentos. Nessa perspectiva, Santos (2009) pontua que a definição sobre população de rua difere bastante entre pesquisadores, pois neste conjunto pode haver migrantes, catadores de papel, profissionais do sexo, trabalhadoresitinerantes, trecheiros ${ }^{1}$, pedintes, desabrigados, camelôs, dentre outros.

Entretanto, o público aqui estudado refere-se, especificamente, ao morador de rua ${ }^{2}$, entendido como a pessoa que vive na rua, que utiliza o espaço da rua como local de moradia. Mendonça (2006, p. 11) caracteriza os moradores de rua como sendo "[...] qualquer pessoa que, sem moradia, pernoita, nos logradouros da cidade, nos albergues ou qualquer outro lugar não destinado à habitação". Mendonça (2006) também destaca um distanciamento quanto ao processo de compreensão do fenômeno moradores de rua, uma vez que a análise de qualquer fenômeno social exige a necessidade de compreender os sujeitos que o vivenciam, compreensão que, segundo o autor, só é possível a partir do desvelamento da subjetividade dos sujeitos envolvidos. Concomitante, é preciso analisar o caráter abstrato, relativo às vontades, anseios e dificuldades do morador de rua, para assim definir suas privações e, por conseguinte, meios de atendê-las. A interpretação acerca das motivações que leva a pessoa a viver na rua perpassa a questão do conflito familiar, abuso de substâncias psicoativas e o desemprego (BRASIL, 2008). Há de se considerar, todavia, que o fato de morar na rua pode ser uma escolha do sujeito, um "estilo de vida" conforme afirma Bordieu (2003). No tocante ao abuso de entorpecentes, é interessante ponderar que os autores Costa

\footnotetext{
1 Santos explicita ainda a diferenciação entre migrantes: aqueles que migram de uma região à outra a procura de trabalho; itinerantes: são "migrantes mal sucedidos", que no seu percurso não encontrou um emprego satisfatório, sendo forçado a voltar para o seu local de origem ou se tornar um morador de rua; e trecheiros: são pessoas que se deslocam, inicialmente, por conta do afastamento da família, e não possuem um noção clara de onde querem chegar (SANTOS, 2009).

$2 \mathrm{O}$ termo morador de rua utilizado neste estudo não se refere à caracterização de estereótipo, mas, apenas reflete um segmento da heterogeneidade da qual é caracterizada a população em situação de rua.
} 
(2005); Snow e Anderson (1998) relatam ser o uso do álcool e outras drogas por parte deste público uma característica incisiva.

\section{MORADORES DE RUA: ORIGEM, REALIDADE E SERVIÇOS PÚBLICOS DE INTERVENÇÃO}

Brito (2011) estuda o processo de urbanização da cidade de Montes Claros (MG) e destaca que o aumento progressivo de habitantes na cidade se justifica pelo crescimento industrial, e, sobretudo, pela ausência de espaços no campo voltados àreprodução familiar, associado às dificuldades de continuidade das atividades tradicionais de cultivo. De acordo com o autor, a implantação de empresas e apoio corrente do governo brasileiro, nas décadas de 1960/1970, aos grandes latifundiários e a criação da monocultura de eucalipto foram substituindo as práticas tradicionais da agricultura familiar, e não houve nessa época, de intensificação do processo de industrialização no Brasil, políticas de incentivo à permanência do homem no campo, nem um projeto de urbanização bem elaborado a cidade foi se formando mediante interesses industriais e econômicos. Destarte, os recursos, serviços, "facilidades, conforto, e emprego" no cenário urbano aliados a precarização da vida no campo funcionam como atrativo ao processo de migração rural:

A demanda pelos locais de moradia com acesso mais fácil ao trabalho e às facilidades urbanas disponibilizadas na área central atrai a população de baixa renda para ocupações clandestinas, cortiços favelas à beira mar dos rios ou morros que circundam as áreas urbanizadas. Algumas pessoas transitaram por essas regiões de pobreza e pelos trabalhos informais e temporários antes de chegarem às ruas [...] (VARANDA; ADORNO, 2004, p. 62).

Segundo Carneiro Junior et al. (1998), a população de rua cresce principalmente nos períodos de recessão econômica, neste sentido "[...] tal expressão tem dado maior visibilidade às suas demandas para diferentes setores da área social, tais como: o da assistência social, da saúde, da habitação e da segurança pública" (CARNEIRO JUNIOR, 1998, p. 48). O autor expressa a nitidez da articulação do fenômeno morador de rua à realidade socioeconômica do país, ou melhor, do capitalismo; em outras palavras concordando com 
Iamamoto e Carvalho (2006) são as expressões da questão social ${ }^{3}$ presente na sociedade, a partir do desenvolvimento do atual sistema capitalista e da consciência por parte da classe pauperizada de sua condição de explorada.

Outro ponto categórico de análise crítica são as ações de caridade ${ }^{4}$, como sopões, doações de vestimentas, dinheiro, entre outras. Mendes e Machado (2004) realizam uma interpretação nesse sentido, pontuando o fato de muitas vezes ao ver um "pedinte" morador de rua, ser um ato quase compulsório por parte da maioria das pessoas em oferecer uma esmola; as autoras indagam:

Não estaríamos destituindo o homem de sua condição de humanidade quando damos uma esmola? Não estaríamos legitimando a posição do pedinte e sua incapacidade de se colocar a trabalho? (CRITELLI, 2003 apud MENDES; MACHADO, 2004, p.2).

A conclusão perceptível em tal fato implica em uma manutenção da condição de vida do morador de rua, a esmola ofertada pode servir para satisfazer sua necessidade momentânea e propiciar um alívio imediato, mas não muda a sua situação, não é condicionante de transformação, pelo contrário, serve como incentivo à inércia.

Em relação às alternativas de intervenção, Pimenta e Silva (2010) abordam que o atendimento ao público que vive na rua demanda um conjunto de serviços públicos articulados. É necessário que ofereçam respostas de modo apropriado e eficiente, mediante apreensão das necessidades apresentadas, tendo em voga a compreensão da subjetividade das demandas sociais, e a incorporação de um atendimento abrangente, o que conforme Ferreira (2006) não é característica das atuais políticas públicas. Este autor pontua duas características concebidas nas políticas públicas de atenção aos moradores de rua:

\footnotetext{
3 lamamoto e Carvalho (2006) definem como questão social: “[...] as expressões do processo de formação e desenvolvimento da classe operária e de seu ingresso no cenário político da sociedade, exigindo seu reconhecimento como classe por parte do empresariado e do Estado. É a manifestação, no cotidiano da vida social, da contradição entre o proletariado e a burguesia, a qual passa a exigir outros tipos de intervenção mais além da caridade e repressão" (IAMAMOTO; MACHADO, 2006, p. 77).

4 Segundo o Dicionário Aurélio (FERREIRA, 1986), caridade significa amor ao próximo, ofertar esmola, favor, benefício. Este conceito é aqui entendido de forma negativa por se opor a direito, isto é, a caridade não apresenta métodos operacionais voltados à resolução da problemática, nem obrigação de prestação de serviços e continuidade dos mesmos(ESTEVÃO, 2007).
} 
A primeira é a de que intervenções setoriais, que visem apenas determinados aspectos do problema, como só a saúde, ou só a geração de emprego e renda, ou só a habitação tendem ao fracasso, na medida em que o fenômeno população de rua é multidimensional por natureza. O segundo aspecto que decorre do primeiro, diz respeito ao tempo e aos custos envolvidos. Normalmente, a implementação e a manutenção de políticas para este tipo de população devem abranger grandes períodos de tempo e acompanhamento (FERREIRA, 2006, p. 16).

A respeito das intervenções setoriais circunscreve, como bem afirma Sposati et al. (2008), o aspecto paliativo da política pública, que é premente de um caráter emergencial e voltado a resultados transitórios, que minimiza a problemática, mas não é capaz de suprimi-la. As autoras ao debruçarem sobre as políticas sociais brasileiras afirmam que elas não possuem o intuito de extinguir as desigualdades, mas sim de sustentá-las segundo interesses políticos, que beneficiem a hegemonia predominante através da minimização dos conflitos sociais.

É nesse sentido que o estudo, tendo o intuito de analisar se os serviços públicos, direcionados aos moradores de rua em Montes Claros (MG) contribuem para com o processo de saída das ruas, utilizou como lócus de coleta de dados o Centro de Referência Especializado para População em Situação de Rua (Centro Pop), o Serviço Especializado em Abordagem Social, e o Consultório na Rua, unidades/serviço que prestam atendimento ao público morador de rua na cidade. Cabe salientar a configuração de cada um destes:

O Centro de Referência Especializado para a População em Situação de Rua (Centro Pop) constitui-se em unidade de referência da Proteção Social Especial de Média Complexidade, de caráter público e estatal, direciona-se, especificamente, para o atendimento especializado à população em situação de rua; tem o intuito de garantir atendimento e ações direcionadas para o desenvolvimento de sociabilidades; oferta trabalho técnico para a análise das demandas dos usuários; presta atendimento diurno de acesso a espaços de guarda pertences, higiene pessoal, alimentação e provisão de documentação civil; e oferece endereço 
institucional para utilização, como referência, da pessoa (BRASIL, 2009b; BRASIL, 2011a).

O Serviço Especializado de Abordagem Social visa garantir um trabalho social de abordagem e busca ativa, que torne possível localizar nos territórios a ocorrência de situação de rua, bem como, a exploração sexual de crianças e adolescentes e trabalho infantil. Realiza a identificação das situações mencionadas e efetua os encaminhamentos, que se façam necessários, para a rede de oferta de serviços (BRASIL, 2009b).

O Consultório na Rua de Montes Claros (MG) constitui uma modalidade de atendimento multidisciplinar da Atenção Primária à Saúde. É um mecanismo clínico-comunitário que propicia cuidados em saúde aos moradores de rua usuários ou não de substâncias psicoativas, em seus próprios contextos de vida, ajustado para atender as peculiaridades de uma população complexa (BRASIL, 2011b).

É interessante frisar que os serviços descritos acima, contam com uma equipe interdisciplinar, dentre as quais a Psicologia e o Serviço Social estão sempre presentes (BRASIL, 2005; BRASIL, 2011b). Em se tratando da atuação do Serviço Social este exerce um papel elementar, pois desenvolve um trabalho social na perspectiva de efetuar uma análise crítica da realidade em que estes usuários se encontram, a identificação das condições materiais em que vivem, e a busca de respostas existentes no âmbito dos serviços de atendimento, tendo em vista a viabilização de acesso dos usuários aos seus direitos (CONSELHO FEDERAL DE SSERVIÇO SOCIAL, 2011).

Um fator imprescindível diz respeito à articulação com a família ${ }^{5}$ no processo de saída das ruas dos sujeitos que nela residem, quando ainda existem vínculos, pois, como disposto pela Constituição Federal de 1988 Art. 226: a família é a base da sociedade, é nela que se assenta as principais formas de proteção e provimento (BRASIL, 1988).

Ademais, pondera-se que o trabalho com moradores de rua em Montes Claros (MG) perpassa pela articulação com outros serviços

5 Conceituada pela Política Nacional de Assistência Social (PNAS) como: grupo de pessoas unidas por laços consanguíneos, afetivos ou de solidariedade (BRASIL, 2005). 
e unidades, tal como: o Centro de Referência Especializado de Assistência Social (CREAS); Centro de Atenção Psicossocial (CAPS AD) (Álcool e outras Drogas); Centro de Atenção Psicossocial (CAPS II) (Sofrimento Mental); Clínicas de Reabilitação; Pastoral de Rua; Estratégia de Saúde da Família (ESF); Unidade de Atendimento Integrado (UAI). Essa articulação se faz imprescindível na garantia de direitos aos moradores de rua e atina-se ao princípio II da Lei Orgânica de Assistência Social (LOAS) que dispõe sobre a universalização dos direitos sociais no sentido de propiciar ao destinatário da ação assistencial o alcance as demais políticas públicas (BRASIL, 1993).

\section{MATERIAIS E MÉTODOS}

A pesquisa realizada neste trabalho, com base em seus objetivos, é classificada como descritiva. Partiu-se de uma inspiração na abordagem crítico-dialética, na qual sebusca observarahistoricidade e a relação conflitiva que entrelaçam o fenômeno em pauta. $O$ estudo utilizou de técnicas de pesquisa tanto da documentação indireta, pesquisa bibliográfica, quanto da documentação direta que se constituiu na realização de estudo transversal de caráter qualitativo (MARCONI; LAKATOS, 2013).

O universo de pesquisa analisado consistiu nos moradores de rua identificados pelas unidades/serviço de atendimento em Montes Claros (MG): Centro de Referência Especializado para População em Situação de Rua (Centro Pop); Serviço Especializado em Abordagem Social e; o Consultório na Rua. Entretanto, em termos do estudo transversal, foi entrevistado tanto o morador de rua, quanto profissionais dos referidos serviços.

Dada a inviabilidade de obter informações de todos os indivíduos que fazem parte do estudo, ou que detém conhecimento destes, optou-se por definir uma amostra do tipo não-probabilística intencional. A amostra constituiu em seis (06) moradores de rua; bem como de dois (02) profissionais de cada unidade/serviço que trabalham com o público pesquisado, totalizando seis (06) profissionais entrevistados.

Utilizou-se de entrevista semiestruturada. Acoleta de dados ocorreu no mês de setembro de 2015. Foram entrevistados moradores de 
rua com tempo de permanência neste espaço acima de 01 ano; de ambos os sexos; cuja faixa etária perpassou de 20 a 50 anos de idade. Os moradores de rua foram abordados individualmente para entrevista, proferida pelas presentes pesquisadoras, acompanhadas por um educador social do Centro Pop e do Serviço Especializado em Abordagem Social que já dispunha de um vínculo com estes. A entrevista com o morador de rua ocorreu tanto nos logradouros públicos de permanência deste, quanto no espaço do Centro Pop. Por sua vez, os profissionais também foram entrevistados individualmente pelas pesquisadoras, em uma sala localizada em seu âmbito de trabalho.

Os dados foram avaliados por meio da técnica de análise de conteúdo. Por se tratar de um estudo que envolve seres humanos, este artigo conta com a aprovação CAAE: 46687515.7.0000.5141 do Comitê de Ética em Pesquisa da Associação Educativa do Brasil (CEP/SOEBRAS), no intuito de garantir a preservação da integridade e dignidade dos sujeitos envolvidos.

\section{RESULTADOS E DISCUSSÃO}

Durante a coleta de dados, notou-se o engajamento dos profissionais que lidam com o público morador de rua, mediante comprometimento com a oferta de respostas positivas. Cabe salientar que foram solícitos com a pesquisa, inclusive pontuaram e incentivaram a realização de estudos acerca da temática. Percebeuse significativa preocupação por parte dos profissionais com a permissão ética para realização da pesquisa, e, sobretudo, com a autorização por parte dos gestores do serviço.Os moradores de rua abordados, por sua vez, também se prontificaram a responder os questionamentos, embora um (01) dentre eles, em primeiro momento, tenha mostrado certa desconfiança.

Os profissionais entrevistados pelas unidades de atendimento específico ao morador de rua em Montes Claros (MG): Centro de Referência Especializado para a População em Situação de Rua (Centro Pop), Serviço Especializado de Abordagem Social e, Consultório na Rua consideram que a causa preponderante dos usuários ${ }^{6}$ atendidos estarem na condição de moradia de rua é

6 Entende-se por usuário as pessoas que são atendidas pelos serviços socioassistenciais (BRASIL, 
em decorrência do abuso de substâncias entorpecentes, seguido dos conflitos familiares (quase sempre ocasionado pelo abuso de drogas). Outras condicionantes ainda são percebidas, mas de forma reduzida, como o desemprego e a ausência de moradia. Os profissionais consideram ainda que os motivos de morar na rua perpassem de forma incisiva à questão do querer, da opção de vida que a pessoa realiza, uma vez que a rua propicia a sensação de liberdade e ausência de regras, seja imposta pela família ou pela sociedade.

Por outro lado, os moradores de rua entrevistados pontuam os seguintes motivos: cinco (05) elencaram o conflito, desapoio, ou dificuldades materiais na vivência familiar, e um (01) o conflito com traficantes na comunidade. Como para alguns são mais de um motivo, uma (01) relatou, ainda, como causa o vicio ao abuso de drogas; um (01) a questão da ausência de emprego e renda, e um (01) outro o próprio querer ir morar na rua.

Nota-se que a percepção dos profissionais quanto às condicionantes de morar na ruaésemelhante aos motivos relatados pelos usuários, entretanto, as proporções relatadas em queessas causas acontecem são um pouco divergentes. O MDS (2008) aborda três (03) motivos que levam a pessoa a viver ou morar na rua, são eles: abuso de substâncias psicoativas, desavença familiar, desemprego. O Terceiro Censo de População em Situação de Rua de Belo Horizonte 7 por sua vez demonstra quatro (04) causas que motivam pessoas a viver/morar na rua: substâncias psicoativas, desavença familiar, desemprego, e ausência de moradia. Neste sentido, as condicionantes do fenômeno morar na rua em Montes Claros - MG para além de contemplar tais características, traz ainda dois novos aspectos: o conflito por conta do tráfico de drogas, e o querer morar na rua como uma escolha por parte da pessoa.

No que concerne aos obstáculos para saírem das ruas, os profissionais entrevistados afirmam que o fator majoritário que inibe a superação de morar na rua é o abuso de drogas, isto é, a dificuldade de resistir à abstinência e de decidir/optar em se

2005). No caso específico deste trabalho, refere-se aos moradores de rua.

$73^{\circ}$ Censo de População em situação de Rua e Migrantes da cidade de Belo Horizonte (PHB DIVULGA..., 2014). 
submeter a um tratamento. Inclusive, todos os profissionais entrevistados pontuaram que um grande entrave enfrentado consiste no próprio querer/escolha do usuário, uma vez que o espaço da rua, mesmo sendo perigoso, oferece também muitos atrativos. Outra complicação se caracteriza na ausência do apoio familiare/ou desistência da família em apoiar o morador de rua por conta de tentativas frustradas. A caridade, oferta de alimentos e dinheiro por parte da sociedade civil também se destacam como um empecilho, uma vez queincentiva a permanência na rua (espaço ondeconsegue o necessário para sobreviver). Apontaram ainda a questão do preconceito e da discriminação como entraves. Em menor proporção, ainda percebe-se a insuficiência econômica e a dificuldade de inserção no mercado de trabalho.

É anuente entre o público em questão a vontade de deixar de morar nas ruas. Chama atenção a fala do entrevistado E10 "Quem quer morar na rua? Você gostaria de morar na rua? Até cachorro quer ter seu lar". Quando questionados sobre os entraves que os inibem de concretizar tal desejo, relatam o vício a droga, a insuficiência econômica, a ausência de apoio familiar ou de incentivo, a dificuldade de conseguir emprego, o fato de não ter onde residir, bem como a questão do próprio querer/decidir sair da rua.

Mendes e Machado (2004) afirmam o aspecto negativo das prestações caritativas, assim como mencionadas pelos profissionais entrevistados, e da percepção dos moradores de rua como vítimas. As autoras salientam que a oferta de roupa, comida, "esmola" a este público reforça a sua condição de subalterno, legitima sua exclusão social e contribui para que o morador de rua, tendo o que deseja nessa condição, assim permaneça. Por outro lado, levando em conta as análises de Bordieu (2003), o fenômeno morar na rua pode ser interpretado como um "estilo de vida", entendido como um conjunto de preferências diversas que expressa a forma como o sujeito vive, suas vestimentas, mobiliários e relacionamentos.

Retomando aos entraves apontados no processo de saída das ruas, Pimenta e Souza (2010) em seus estudos, demonstram o não interesse por parte da família, e mesmo do morador de rua, em 
não querer restabelecer o vínculo familiar entre si. Embora esses autores reconheçam a importância da família como veículo ao retorno à vida social antes estabelecida, consideram que a família não é mecanismo suficiente para corroborar tal modificação, enfatizando a necessidade de serviços públicos articulados, especialmente os referentes à Política de Assistência Social.

Destarte, no que se refere aos laços de afetividade e inter-relação com a família, quatro (04) dos moradores de rua pesquisados relatam manter contato com algum membro de sua família; ao passo que dois (02) deles não possuem mais vínculo algum com a família e nem desejam restabelecê-lo. Tanto os profissionais dos serviços, quanto os moradores de rua afirmam que é assegurado à autonomia ${ }^{8}$ do usuário neste sentidode não querer nenhum tipo de aproximação com a família. A autonomia do usuário é um dos princípios da Política Nacional de Assistência Social, expresso no capítulo II, seção I, artigo $4^{\circ}$ inciso III da Lei Orgânica de Assistência Social (LOAS) e da Lei Orgânica de Saúde (LOS) designado pelo capítulo II, artigo $7^{\circ}$ inciso III.

A relação do morador de rua com a família é uma questão que engloba diversos fatores, como pontua os entrevistados: a questão da perda de vínculos afetivos ocasionadopor algum tipo de conflito; vergonha por parte do morador de rua, decorrente de sua situação de espoliação; não aceitação dos moradores de rua às normas e padrão de vida impostas pela sua família.Os profissionais afirmam que sempre que possível, e consentido pelos usuários, eles buscam realizar a aproximação deste com sua família, pois se entende que o apoio familiar é imprescindível à transformação de vida desses sujeitos.

Um dado importante consiste no fato de que todos os moradores de rua entrevistados fazem uso de algum tipo de droga, seja ela lícita ou ilícita, sendo o abuso do álcool uma característica comum entre eles. Costa (2005) salienta que o abuso do álcool e/ou outras drogas fazem parte do cotidiano daqueles que vivem na rua "[...] seja como alternativa para minimizar a fome e o frio, seja como

8 A autonomia, neste contexto, significa considerar a capacidade e liberdade de decisão do usuário, como sujeito de sua história, e que tem o direito de optar pelo o que considera melhor para si mesmo (BRASIL, 2009a). 
elemento de socialização entre os membros dos grupos de rua" (COSTA, 2005, p. 9). Snow e Anderson (1998) expõem que o uso de álcool e drogas é caracterizado como um aspecto cultural do "estilo de vida" da população que vive na rua.

No que se refere ao processo de implementação das atividades concernentes aos serviços direcionadosa atender os moradores de rua em Montes Claros (MG), os profissionais afirmam que existem muitas dificuldades/desafios. Relatam a questão da burocracia e morosidade da rede de atendimento dos serviços públicos, bem como o quantitativo reduzido e às vezes inexistentes de alguns serviços de atenção as necessidades dos moradores de rua, tal como a República, Albergue e Leitos Hospitalares. Mencionaram quanto ao processo demorado na construção de vínculos com o usuário do serviço, e a habilidade em lidar com a frustração na resolução de muitos casos, além da perda constante de documentação pessoal por parte do usuário. Apontaram também quanto à escassez de alguns recursos materiais para concretização do serviço, tal como:indisponibilidade de veículo e internet, que mesmo não sendo um grande empecilho, atrapalha na concretização das atividades. No caso do Centro Pop, identificase, ainda, a rotatividade de mudança do local de funcionamento da unidade, a distância dos locais de permanência dos usuáriose a estrutura desfavorável do espaço em que se localiza atualmente.

De modo geral, os moradores de rua entrevistados afirmam que os serviços cumprem com a oferta de atividades básicas. No entanto, relatam a ineficácia do conjunto dos serviços de atendimento, tanto aqueles específicos aos moradores de rua, como os outros, destacando a demora no processo de atendimento às suas necessidades e o baixo nível de resolução das situações em que se encontram. É consenso também entre os moradores de rua entrevistados, tanto aqueles que frequentam quanto os que não frequentam o Centro Pop, que a localização da unidade é imprópria, distante dos seus locais de permanência (área central da cidade). No que concerne ao acesso aos serviços, identifica-se que três (03) deles não recebem atendimento do Consultório na Rua, um (01) não é atendido pela Abordagem Social, e três (03) não frequentam o Centro Pop. 
Em comparação ao disposto pela Tipificação Nacional de Serviços Socioassistenciais9 (BRASIL, 2009b), o Serviço Especializado de Abordagem Social em Montes Claros (MG), de modo geral, cumpre com as prerrogativas estipuladas. O Centro Pop também operacionaliza as atividades de acordo com as especificações deste documento supracitado, entretanto, a localização e a estrutura atual do Centro Pop contrariam as orientações da Secretaria Nacional de Renda e Cidadania, Secretaria Nacional de Assistência Social e do Ministério do Desenvolvimento Social e Combate à Fome (MDS) (BRASIL, 2011b) que consideram como local de implantação da unidade a área com maior concentração deste público, de fácil acesso, ou seja, na região central do município, bem como, preconizam a existência de espaço apropriado e acessível. Quanto ao Consultório na Rua de Montes Claros, ainda que perpassado por desafios, está em consonância com as diretrizes e prerrogativas estabelecidas pelo Ministério da Saúde (BRASIL, 2011b), Portaria Nº 2.488 .

Pimenta e Silva (2010) ponderam a importância dos programas previstos na Política Pública de Assistência Social mediante a LOAS e o Sistema Único de Assistência Social (SUAS) aos moradores de rua, população altamente vulnerável; em uma análise a realidade do atendimento ao morador de rua em um município de grande porte no interior do Estado de São Paulo, relatamque o SUAS já foi implantado, mas como ainda é um sistema recente, não está completamente institucionalizado. Os autores ainda situam a necessidade do trabalho em rede ${ }^{10}$, e sua inoperância neste município. As contribuições do estudo de Pimenta e Silva (2010) possibilitam visualizar as dificuldades de materialização de serviços públicos articulados que abarque a problemática da moradia na rua, tal como também acontece em Montes Claros (MG).

No que diz respeito às condições de vida do público em pauta, é consenso entre os moradores de rua entrevistados que morar

9 A Tipificação Nacional de Serviços Socioassistenciais é um documento aprovado pelo Conselho Nacional de Assistência Social (CNAS), por meio da Resolução nº 109, de 11 de novembro de 2009, que tipifica e padroniza em todo território nacional os serviços de proteção social básica e especial da Política de Assistência Social (BRASIL, 2009b).

10 Entende-se aqui como trabalho em rede a articulação entre os serviços de atendimento ao público em questão (BRASIL, 2005). 
na rua é ruim, difícil, desconfortável e perigoso; que a obtenção de comida não se caracteriza como um problema, ao contrário, é de fácil acesso, seja ofertado pelo Centro Pop, pela sociedade em geral, e preferencialmente pelas empresas que trabalham com a venda de comida; que há dificuldade de tomar banho; bem como, que o preconceito e discriminação por parte da população é explicita e humilhante. Por sua vez, um (01) dos entrevistados afirma que acostumoua viver/dormir na rua, e que isto lhe traz a sensação de liberdade:"Passei muito tempo preso [...] Se for pra dormi entre quatro (04) paredes acho que não consigo mais. $\mathrm{Na}$ rua é bom, é tudo aberto, é livre" (E11).

Costa (2005, p. 11) pontua que "[...] a rua é vivida como um espaço de instabilidade [...] sobreviver na rua é uma façanha individual”. As pessoas que vivem na rua sofrem as mais variadas formas de violações, a dignidade da pessoa humana a eles é negada; e estes criam estratégias próprias para sobreviverem. A autora frisa ainda que a presença do Estado tem sido relativa na garantia de direitos sociais a este público.

A realidade das condições de vida dos moradores de ruanão condiz com o disposto pelo ordenamento jurídico maior do país, a Constituição Federal de 1988, que em seu Capítulo II, dos direitos sociais, Artigo $6^{\circ}$ assegura a garantia "[...] a saúde, a alimentação, o trabalho, a moradia, o lazer, a segurança, a previdência social, a proteção à maternidade e à infância, a assistência aos desamparados" (BRASIL, 1988).

No que se refere à percepção dos profissionais quanto à contribuição do serviço para o processo de saída das ruas, é consenso entre eles que sim, pois o suporte ofertado pelo serviço desde garantias básicas de sobrevivência, orientação, incentivo e informação tem possibilitado condições para que os usuários atendidos abandonem a situação de moradia de rua.

Todavia, Ferreira (2006) pontua que o processo de saída das ruas não é algo fácil, ao contrário, é permeado de complexidades, sobretudo para aqueles que vivem há muito tempo nas ruas. Este autor ainda salienta que o fenômeno morar na rua é multifacetado, daí a necessidade de políticas sociais abrangentes para atender positivamente as especificidades deste público. Neste sentido, 
Pimenta e Silva (2010) veem destacar que a efetividade de garantias a este público perpassa a ação do Poder Público, e que infelizmente ainda são realizadas de forma paliativas e emergenciais.

Um dado relevante obtido na pesquisa consiste no fato de que todos os moradores de rua entrevistados exercem algum tipo de atividade remunerada, embora seja de caráter informal. Tal constatação permite refutar como afirma Mattos e Ferreira (2004) e Costa (2005) a concepção, por parte de grande parcela da sociedade, de que o morador de rua é vagabundo, "ganha à vida de forma fácil”. Aliás,a Pesquisa Nacional sobre a População em Situação de Rua, MDS (BRASIL, 2008), demonstra que 70,9\% da população em situação de rua no país exercem algum tipo de trabalho.

Nestes termos, percebe-se que a realidade do público morador de rua éperpassada por diversas complexidades, desde condicionantes multicausais; entraves constantes da vida diária, inclusive no que diz respeito à própria sobrevivência; serviços públicos que ainda não contemplam as suas necessidades em amplitude e; estereótipos, mitos e preconceitos relacionados ao ser morador de rua.

\section{CONSIDERAÇÕES FINAIS}

Constatou-se que as causas que condicionam os moradores de rua a habitarem em tal espaço em Montes Claros (MG) perpassam fatores multicausais, uns amplamente discutidos pela política de atenção a este público e nas literaturas referentes a esta temática, como a questão do conflito familiar, abuso de substâncias psicoativas, ausência de moradia e desemprego; outras, parcamente mencionadas: a problemática do conflito com traficantes de drogas e o querer viver na rua. Percebe-se que a ida para a rua reforça essas condicionantes que os motivaram a ali residir; são entraves que se alargam e somam a outros com o prolongamento da permanência nas ruas.

A pesquisa permitiu identificar ainda que os serviços sociais direcionados aos moradores de rua em Montes Claros (MG), em conjunto com demais serviços da rede de atendimento no município, tem corroborado expressiva mudança nas condições de vida dos usuários. Entretanto, é explícito que barreiras e desafios 
são comumente vivenciados no processo de materialização desses serviços, que são intercaladas pela morosidade dos procedimentos interventivos, burocracia e precariedade de investimentos públicos; características típicas da atual conjuntura neoliberal. É inevitável frisar a problemática da localização atual do Centro Pop, uma contrariedade significativa à política de atendimento ao morador de rua e que expressa um desrespeito aos usuários do serviço.

Neste sentido, estes três pontos elencados acima: causas, entraves, e serviços de atendimento, que estão inter-relacionados comas hipóteses de pesquisa, são preponderantemente confirmadas. Os aspectos latentes nas suposições consistem em não considerar, a princípio, que o morador de rua pudesse optar por estar neste espaço,bem como, que o fato do tráfico de drogas pudesse ocasionar conflitos que desembocaria na expulsão do sujeito da sua propriedade (condicionando-o a viver na rua).

É pertinente uma reflexão acerca do fenômeno morar na rua como uma escolha por parte do sujeito, pois considerar e interpretar tal aspecto exige uma visão holística da realidade, para além do "estilo de vida" que a sociedade capitalista coloca como ideal. Isto é, quem disse que a felicidade está circunscrita ao fato de ter uma moradia, emprego e renda em amplitudee uma relação harmoniosa com a família? Ou melhor, não se pode afirmar que seja issoque o morador de rua anseia. E muito menos impor tais circunstâncias à sua vida.

No entanto, entender que o morador de rua tem a autonomia de permanecer na rua, caso queira, não implica a desassistência a este público, ao contrário, o que se defende é a materialização de políticas públicas eficientes para atender suas especificidades. $O$ debate deve ser direcionado para a garantia de direitos e qualidade de vida do morador de rua, mediante respeito a suas trajetórias de vida e escolhas, fortalecendo a capacidade de empoderamento e autonomia destes sujeitos.

Salientam-se nossos sinceros agradecimentos aos participantes deste estudo, profissionais do Centro Pop, Abordagem Social, Consultório na rua e, usuários destes serviços, que dispuseram alguns minutos do seu tempo para responder os questionamentos da entrevista. 
Cabe deixar nítido que o presente estudo não tem a pretensão de firmar um conhecimentodefinitivoacerca da temática investigada, mas contribuir com a análise da questão, e sinalar apontamentos que incentivem o atendimento e demais pesquisas referentes ao morador de rua. Pondera-se, ainda, a importância de mais estudos sobre o assunto, inclusive no que diz respeito a outros segmentos da população em situação de rua, tal como a realidade dos migrantes, itinerantes, trecheiros.

\section{REFERÊNCIAS}

BRASIL. Secretaria Nacional de Renda e Cidadania; Secretaria Nacional de Assistência Social. Orientações técnicas: Centro de Referência Especializado para População em Situação de Rua Centro Pop. v. 3.Brasília (DF),2011a.

BRASIL. Ministério da Saúde. Portaria n² 2.488, de 21 de outubro de 2011. Aprova a Política Nacional de Atenção Básica. Brasília (DF), 2011b.

BRASIL. Presidência da República. Decreto n. 7.053 de 23 de dezembro de 2009. Política Nacional para a População em Situação de Rua. Brasília (DF), $2009 a$.

BRASIL. Secretaria Nacional de Assistência Social. Tipificação Nacional de Serviços Socioassistenciais. Brasília (DF), 2009b.

BRASIL. Secretaria de Avaliação e Gestão da Informação. Pesquisa Nacional sobre a População em Situação de Rua. Brasília (DF), 2008.

BRASIL. Ministério do Desenvolvimento Social e Combate à Fome. Política Nacional de Assistência Social - PNAS/2004 e Norma Operacional Básica NOB/SUAS. Brasília (DF), 2005.

BRASIL. Presidência da República. Lei n 8.742, de 7 de dezembro de 1993. Lei Orgânica da Assistência Social. Brasília (DF), 1993.

BRASIL. Constituição da Republica Federativa do Brasil. Brasília (DF): Senado Federal, 1988.

BOURDIEU, Pierre. Gostos de Classe e Estilos de Vida. In: ORTIZ,Renato (Org.). A Sociologia de Pierre Bourdieu. São Paulo: Olho D’água, 2003. 
BRITO, Giliarde de Souza. Migrações rural/urbano e fluxos de conhecimento agroecológico: o caso de Montes Claros, Minas Gerais. Montes Claros: Instituto de Ciências Agrárias/Universidade Federal de Minas Gerais Campus Regional de Montes Claros, 2011.

CARNEIRO JUNIOR, Nivaldo et al. Serviços de saúde e população de rua: contribuição para um debate. Saúde e Sociedade, v. 7, n.2, p. 47-62, 1998. Disponível em: <http://www.scielo.br/pdf/sausoc/ v7n2/05.pdf>. Acesso em: 25 mar. 2015.

CONSELHO FEDERAL DE SERVIÇO SOCIAL. Parâmetros para Atuação de Assistentes Sociais na Política de Assistência Social. Brasília (DF), 2011. (Série Trabalho e Projeto Profissional nas Políticas Sociais).

COSTA, Ana Paula Motta. População em situação de rua: contextualização e caracterização.Textos \& Contextos, Porto Alegre, v. 1, n. 4, p. 1-15, dez. 2005. Disponível em: <http:// revistaseletronicas.pucrs.br/ojs/index.php/fass/article/ viewArticle/993>. Acesso em: 15 out. 2015.

ESCOREL, Sarah. Vivendo de teimoso: moradores de rua da cidade do Rio de Janeiro. In: BURSZTYN, Marcel (Org.). No meio da rua: nômades, excluídos e viradores. Brasília (DF): Garamond, 2000.p. 139-171.

ESTEVÃO, Ana Maria Ramos. O que é Serviço Social. 6. ed. São Paulo: Brasiliense, 2007.

FERREIRA, Aurélio Buarque de Holanda. Novo dicionário da língua portuguesa. Nova Fronteira, 1986.

FERREIRA, Frederico Poley Martins. População em situação de rua, vidas privadas em espaços públicos:o caso de Belo Horizonte 1998-2005. Belo Horizonte: Secretaria de Planejamento e Gestão do Estado de Minas Gerais, 2006.

IAMAMOTO, Marilda Vilela; CARVALHO, Raul. Relações Sociais e Serviço Social no Brasil: esboço de uma interpretação históricometodológica. 19. ed. São Paulo: Cortez, 2006.

MATTOS, Ricardo Mendes; FERREIRA, Ricardo Franklin. Quem vocês pensam que (elas) são? Representações sobre as pessoas em situação de rua. Psicologia e Sociedade, v. 16, n. 2, p. 47-58, 
maio/ago.2004. Disponível em: <http://www.scielo.br/pdf/psoc/ v16n2/a07v16n2>. Acesso em: 17 maio 2015.

MARCONI, Marina de Andrade; LAKATOS, Eva Maria. Técnicas de Pesquisa. 7. ed. São Paulo: Atlas, 2013.

MENDES, Aline Aguiar; MACHADO, Maria Fernanda. Uma clínica para o atendimento a moradores de rua: direitos humanos e composição do sujeito. Psicologia ciência e profissão, Brasília (DF),v. 24, n. 3, p. 100-105, set. 2004. Disponível em: <http://pepsic.bvsalud.org/scielo.php?script=sci_arttext\&pid =S1414-98932004000300013>. Acesso em: 10 ago. 2015.

MENDONÇA, Gabriel Coelho. Sentidos subjetivos de moradores de rua frente ao futuro. Campinas: Pontifícia Universidade Católica de Campinas, 2006.

PBH DIVULGA o $3^{\circ}$ Censo de População em situação de Rua e Migrantes. Sala de Notícias, Belo Horizonte, 30 abr. 2014. Disponível em: <http://portalpbh.pbh.gov.br/pbh/ecp/noticia.do ?evento=portlet\&pAc=not\&idConteudo=154144\&pldPlc=\&app =salanoticias $>$. Acesso em: 11 abr. 2015.

PIMENTA, Carlos Alberto Máximo; SILVA, Cláudia Lúcia. Moradores de rua e realidade social contemporânea: subsídios para intervenções no município de Taubaté (SP). Revista Brasileira de Gestão e Desenvolvimento Regional, v. 6, n. 3, 2010. SANTOS, Daiane dos Santos. O retrato do morador de rua da cidade de Salvador (BA): um estudo de caso.2009. $71 \mathrm{f}$. Curso de Pós-Graduação Lato Sensu (Especialização Direitos Humanos e Cidadania)-Fundação Escola do Ministério Público, Salvador, 2009.

SNOW, David; ANDERSON, Leon. Desafortunados: um estudo sobre o povo da rua. Petrópolis: Vozes, 1998.

SPOSATI, Aldaíza de Oliveira; et al. A assistência na trajetória das políticas sociais brasileiras: uma questão em análise. 10. ed. São Paulo: Cortez, 2008.

VARANDA, Walter; ADORNO, Rubens de Camargo Ferreira. Descartáveis urbanos: discutindo a complexidade da população de rua e o desafio para políticas de saúde. Saúde e sociedade, v. 13, n. 1, p. 56-69, jan./abr.2004. 
VIEIRA, Maria Antonieta da Costa; BEZERRA, Eneida Maria Ramos; ROSA, Cleisa Moreno Maffei (Orgs.). População de rua: quem é, como vive, como é vista. 3. ed. São Paulo: Hucitec, 2004. 